\title{
Current controversies in determining the main mechanisms of atrial fibrillation
}

Citation for published version (APA):

Schotten, U., Dobrev, D., Platonov, P. G., Kottkamp, H., \& Hindricks, G. (2016). Current controversies in determining the main mechanisms of atrial fibrillation. Journal of Internal Medicine, 279(5), 428-438. https://doi.org/10.1111/joim.12492

Document status and date:

Published: 01/05/2016

DOI:

10.1111/joim.12492

Document Version:

Publisher's PDF, also known as Version of record

Document license:

Taverne

Please check the document version of this publication:

- A submitted manuscript is the version of the article upon submission and before peer-review. There can be important differences between the submitted version and the official published version of record.

People interested in the research are advised to contact the author for the final version of the publication, or visit the DOI to the publisher's website.

- The final author version and the galley proof are versions of the publication after peer review.

- The final published version features the final layout of the paper including the volume, issue and page numbers.

Link to publication

\footnotetext{
General rights rights.

- You may freely distribute the URL identifying the publication in the public portal. please follow below link for the End User Agreement:

www.umlib.nl/taverne-license

Take down policy

If you believe that this document breaches copyright please contact us at:

repository@maastrichtuniversity.nl

providing details and we will investigate your claim.
}

Copyright and moral rights for the publications made accessible in the public portal are retained by the authors and/or other copyright owners and it is a condition of accessing publications that users recognise and abide by the legal requirements associated with these

- Users may download and print one copy of any publication from the public portal for the purpose of private study or research.

- You may not further distribute the material or use it for any profit-making activity or commercial gain

If the publication is distributed under the terms of Article $25 \mathrm{fa}$ of the Dutch Copyright Act, indicated by the "Taverne" license above, 


\title{
Current controversies in determining the main mechanisms of atrial fibrillation
}

\author{
U. Schotten ${ }^{1}$, D. Dobrev², P. G. Platonov ${ }^{3}$, H. Kottkamp ${ }^{4}$ \& G. Hindricks ${ }^{5}$ \\ From the ${ }^{1}$ Cardiovascular Research Institute Maastricht, Maastricht Centre of Systems Biology, Maastricht University, Maastricht, \\ The Netherlands; ${ }^{2}$ Institute of Pharmacology, West German Heart and Vascular Center, School of Medicine, University Duisburg-Essen, \\ Essen, Germany; ${ }^{3}$ Center for Integrative Electrocardiology at Lund University (CIEL), Arrhythmia Clinic, Skåne University Hospital, Lund, \\ Sweden; ${ }^{4}$ Department of Rhythmology, Klinik Hirslanden, Zürich, Switzerland; and ${ }^{5}$ Department of Cardiac Electrophysiology, Heart Center, \\ University of Leipzig, Leipzig, Germany
}

Content List - Read more articles from the symposium: Atrial fibrillation - from atrial extrasystoles to atrial cardiomyopathy. What have we learned from basic science and interventional procedures

Abstract. Schotten U, Dobrev D, Platonov PG, Kottkamp H, Hindricks G (Cardiovascular Research Institute Maastricht, Maastricht Centre of Systems Biology, Maastricht University, Maastricht, The Netherlands; Institute of Pharmacology, West German Heart and Vascular Center, School of Medicine, University Duisburg-Essen, Essen, Germany; Center for Integrative Electrocardiology at Lund University (CIEL) and Arrhythmia Clinic, Skåne University Hospital, Lund, Sweden; Klinik Hirslanden, Zürich, Switzerland; and Heart Center, University of Leipzig, Leipzig, Germany). Current controversies in determining the main mechanisms of atrial fibrillation (Review Symposium). J Intern Med 2016; 279: 428-438.

Despite considerable basic research into the mechanisms of atrial fibrillation (AF), not much progress has been made in the prognosis of patients with AF. With the exception of anticoagulant therapy, current treatments for AF still do not improve major cardiovascular outcomes. This may be due partly to the diverse aetiology of AF with increasingly more factors found to contribute to the arrhythmia. In addition, a strong increase has

\section{Introduction}

Since the 1990s there has been a tremendous increase in basic research to investigate the mechanisms of atrial fibrillation (AF) with increasing attention from the scientific community in terms of both allocated resources and scientific output. While the resulting understanding of the pathomechanisms of AF has grown steadily, the major clinical outcomes of AF patients have improved only marginally. Antiarrhythmic drug treatment can often not prevent recurrences of AF. Catheter been seen in the technological complexity of the methods used to quantify the main pathophysiological alterations underlying the initiation and progression of AF. Because of the lack of standardization of the technological approaches currently used, the perception of basic mechanisms of AF varies widely in the scientific community. Areas of debate include the role of $\mathrm{Ca}^{2+}$-handling alterations associated with AF, the contribution and noninvasive assessment of the degree of atrial fibrosis, and the best techniques to identify electrophysiological drivers of AF. In this review, we will summarize the state of the art of these controversial topics and describe the diverse approaches to investigating and the scientific opinions on leading AF mechanisms. Finally, we will highlight the need for transparency in scientific reporting and standardization of terminology, assumptions, algorithms and experimental conditions used for the development of better AF therapies.

Keywords: atrial fibrillation, $\mathrm{Ca}^{2+}$-handling, fibrosis, multiple wavelet hypothesis, rotors.

ablation, originally developed for treatment of paroxysmal AF, has a limited efficacy in patients with persistent $\mathrm{AF}$ and anticoagulation therapy, even since the introduction of the novel oral anticoagulants, is still associated with potentially harmful side effects.

The lack of improvement in clinical outcomes in AF may partially reflect our inability to detect individual disease mechanisms underlying the arrhythmia in individual patients. The multifactorial aetiology of AF has been recognized for many 
years but so far individual disease mechanisms cannot be reliably identified by easily accessible clinical signs and symptoms [1]. Closing this 'translational gap' by linking the diverse pathomechanisms to sets of phenotypic features in patients is among the most important challenges in cardiac research in general and in the field of $\mathrm{AF}$ in particular [2].

Another reason for the slow improvement of current AF therapies may be related to the complexity of the basic research related to this field. Very different and increasingly more sophisticated technological approaches are being used to unravel basic AF mechanisms. Definitions, assumptions and algorithms used in these technical approaches vary widely and have resulted in fundamentally different perceptions even of very basic mechanisms of AF.

Here, we will provide a brief overview of some of these controversial areas of AF research. Specifically, we will discuss the contribution of $\mathrm{Ca}^{2+}$ handling alterations and the role of atrial fibrosis in AF as well as the still debated issue of the prevailing conduction patterns during AF.

\section{$\mathrm{Ca}^{2+}$-handling instability versus $\mathrm{Ca}^{2+}$-signalling silencing}

It is likely that the limited efficacy of current pharmacological treatment options result from an incomplete understanding of AF pathophysiology. Focal ectopic firing is required for the initiation of AF in a vulnerable substrate, but can also maintain AF when it occurs repetitively at a high frequency. While reentry is a well-accepted mechanism of AF, the contribution of ectopic (triggered) activity caused by delayed afterdepolarizations (DADs), which depend on abnormalities of $\mathrm{Ca}^{2+}$ handling, is less clear and somewhat controversial [3].

Recent studies in small and large animal models of AF have provided evidence for and insights into the potential molecular basis of DAD-mediated triggered activity. Important roles for ryanodine receptor (RyR2) dysfunction, increased sarcoplasmic reticulum (SR) $\mathrm{Ca}^{2+}$ leak and spontaneous $\mathrm{Ca}^{2+}$ release events in pacing-induced $\mathrm{AF}$ have been suggested by the results of experimental studies in mice lacking the RyR2-stabilizing subunit FKBP12.6, carrying an E169K mutation in junctophilin-2 or with gain-of-function mutations predisposing to catecholaminergic polymorphic ventricular tachycardia (CPVT) [4-7]. Pharmacological inhibition of $\mathrm{Ca}^{2+} /$ calmodulin-dependent protein kinase type-II (CaMKII), genetic inhibition of CaMKII-dependent RyR2-Ser2814 phosphorylation and the RyR2-stabilizing compound S107 prevent AF initiation in FKBP12.6 knock-out mice, also supporting a critical role for RyR2 dysfunction in AF vulnerability [6-8].

Findings from large animal models of AF also indicated a role of $\mathrm{Ca}^{2+}$-handling abnormalities in AF pathophysiology. Dogs with persistent AF show hyperphosphorylated RyR2 and increased RyR2 open probability [9]. Experimental heart failure increases SR $\mathrm{Ca}^{2+}$ load and promotes cellular triggered activity, which involves increased CaMKII but reduced RyR2 expression with unaltered phosphorylation [10]. In goats with persistent AF, SR $\mathrm{Ca}^{2+}$ uptake is reduced, whereas CaMKII-dependent RyR2 phosphorylation is increased, which is likely to increase SR $\mathrm{Ca}^{2+}$ leak [11]. $\mathrm{Ca}^{2+}$-handling abnormalities along with a higher incidence of DADs also occur in right atrial cardiomyocytes from patients with persistent AF, suggesting $\mathrm{Ca}^{2+}$ handling instability in AF patients [12-14]. Increased CaMKII function with subsequent CaMKII-dependent RyR2 hyperphosphorylation appears to play a key role in diastolic SR $\mathrm{Ca}^{2+}$ leak and cellular triggered activity in patients with persistent AF [7, 13, 14]. Taken together there is now compelling evidence in animal models and in patients for a role of DAD-mediated cellular triggered activity in patients with persistent AF. However, despite the occurrence of DADs and cellular triggered activity in human atrial cardiomyocytes from patients with persistent $\mathrm{AF}$ in vitro, it is not clear whether DADs can also occur during AF in vivo and, if so, how they contribute to the fibrillatory process maintaining AF (Fig. 1).

There is evidence from a rabbit model that sustained high atrial activation rates per se do not increase SR $\mathrm{Ca}^{2+}$ leak despite hyperphosphorylation of the RyR2 [15]. Computational analysis suggested that the strongly reduced RyR2 expression in this model may offset the effects RyR2 hyperphosphorylation on SR $\mathrm{Ca}^{2+}$ leak. $\mathrm{Ca}^{2+}$-wave propagation to the myocyte centre was impaired in both rabbits and patients with persistent AF, which is likely to be due to an increase in $\mathrm{Ca}^{2+}$-buffering strength along with a reduction in intracellular $\mathrm{Na}^{+}$concentration following rapid atrial pacing. Atrial tachycardia remodelling in dogs also induces impaired $\mathrm{Ca}^{2+}$-wave propagation to the cell centre [16]. Together, these data suggest that sustained high atrial rates per se may not produce $\mathrm{Ca}^{2+}$-handling instability and 


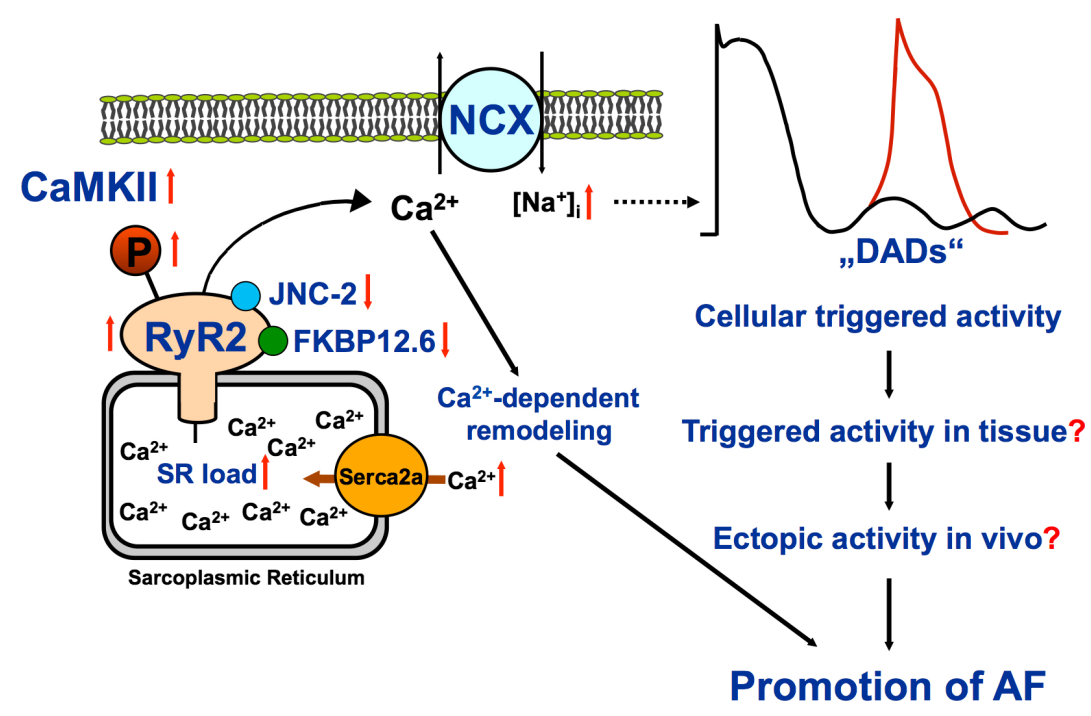

Fig. 1 Molecular determinants of the generation of delayed after depolarization (DAD) and cellular triggered activity in patients with paroxysmal and chronic atrial fibrillation (AF). Red upward and downward arrows indicate factors that are increased or decreased in AF patients, respectively. Question marks indicate areas of uncertainty that need to be further studied. JNC-2, junctophilin-2; RyR2, ryanodine receptor; CaMKII, $\mathrm{Ca}^{2+} /$ calmodulin-dependent protein kinase type-II; NCX, $\mathrm{Na}^{+} / \mathrm{Ca}^{2+}$-exchanger; SERCA2a, SR $\mathrm{Ca}^{2+}$-ATPase. See main text for further details.

indicate the possibility that these $\mathrm{Ca}^{2+}$-handling abnormalities including increased SR $\mathrm{Ca}^{2+}$ leak in patients with persistent AF might result from the accompanying cardiovascular diseases rather than from AF itself. In addition, it appears that once AF persists the high atrial rate may cause $\mathrm{Ca}^{2+}$-handling silencing to counteract the potentially cytotoxic effects of chronically elevated intracellular $\mathrm{Ca}^{2+}$ levels. Therefore, it could be speculated that depending on the underlying cardiovascular conditions, either proarrhythmic $\mathrm{Ca}^{2+}$-handling abnormalities or arrhythmia-suppressing $\mathrm{Ca}^{2+}$-handling silencing might prevail, highlighting the need for appropriate substrate classification and tailored $\mathrm{Ca}^{2+}$-handling targeting in an individual AF patient. Furthermore, $\mathrm{Na}^{+}$homeostasis has a very important impact on the function of various ion channels and transporters [17]. Findings from experimental models suggest that atrial tachycardia and $\mathrm{AF}$ reduce $\mathrm{Na}^{+}$load [15] which, if also the case in human AF, paradoxically may contribute to $\mathrm{Ca}^{2+}$ depletion and prolongation of the action potential.

Another inconsistency in the field is the discrepancy between results from experiments in isolated human atrial cardiomyocytes and in human atrial trabecular tissue. Although $\mathrm{Ca}^{2+}$-handling instability has been reported in human atrial myocytes $[14,18]$, in human atrial trabeculae spontaneous activity defined as abnormal aftercontractions is less common in tissue from patients with $\mathrm{AF}$ as compared to those in sinus rhythm [19]. These results may be due to the fact that the $\mathrm{Na}^{+}$ concentration in isolated myocytes is altered by the concentration of the ion in the patch pipette, which is not the case in atrial trabeculae. Further work is needed to specifically address this important but underinvestigated area.

It could be speculated that during AF instead of contributing to DAD development the persistent SR $\mathrm{Ca}^{2+}$ leak may initiate $\mathrm{Ca}^{2+}$-dependent pathways, thereby contributing to the remodelling process that promotes the transition of $\mathrm{AF}$ to more persistent forms of AF. Evidence supporting such a concept was provided by Li et al. [20] in studies in mice with cardiac-restricted overexpression of a repressor form of the cAMP response element modulator (CREM-TG mice), which exhibit atrial dilatation, abnormal cardiomyocyte growth, mild atrial fibrosis, reduced expression of connexin-40 and $\mathrm{Ca}^{2+}$ handling abnormalities including increased SR $\mathrm{Ca}^{2+}$ leak. CaMKII-dependent hyperphosphorylation of the RyR2 and SR $\mathrm{Ca}^{2+}$ leak are likely to be early events in the spontaneous development of AF in CREM-TG mice, because spontaneous $\mathrm{AF}$ is eliminated when these animals are crossed with RyR2-S2814A-TG mice resistant to CaMKII-dependent 
RyR2 hyperphosphorylation. In addition, these authors demonstrated that the development of AF substrate was directly linked to excess RyR2mediated SR $\mathrm{Ca}^{2+}$ leak and that excess RyR2mediated SR $\mathrm{Ca}^{2+}$ leak in CREM-TG mice stimulated the calcineurin-NFAT pathway associated with atrial dilatation and decreased connexin-40 expression associated with decreased conduction velocity [20]. Mice with a RyR2 CPVT mutation causing increased SR Ca ${ }^{2+}$ leak and mouse hearts with acutely elevated intracellular $\mathrm{Ca}^{2+}$ levels also showed decreased atrial conduction velocity [21]. The underlying mechanisms appear to involve both acute $\mathrm{Ca}^{2+}$-dependent inhibition of $\mathrm{Na}^{+}$channels and chronic downregulation of Nav1.5 expression [22]. Most importantly, normalization of the RyR2mediated $\mathrm{Ca}^{2+}$ leak in CREM-TG mice prevented the development of both atrial dilatation and conduction velocity reduction [20]. This suggests that RyR2-mediated SR $\mathrm{Ca}^{2+}$ leak may drive AF progression via these and possibly other remodelling pathways, thereby potentially contributing to $\mathrm{AF}$ maintenance by structural remodelling and reentry.

Finally, right atrial cardiomyocytes from patients with paroxysmal AF, who had been in sinus rhythm at the time of tissue procurement for several weeks, also exhibited an increased incidence of DADs and cellular triggered activity [18]. The underlying molecular substrate involves increased SR $\mathrm{Ca}^{2+}$ load and RyR2 dysregulation, with the latter resulting from increased protein expression and higher single-channel open probability. A relative deficiency of the RyR2-stabilizing protein junctophilin-2, due to increased RyR2 but unaltered junctophilin-2 expression, might explain the RyR2 dysfunction, although the precise mechanisms of $\mathrm{SR} \mathrm{Ca}^{2+}$ leak in patients with paroxysmal AF are still incompletely understood. Further work is needed to delineate the molecular mechanisms of increased cellular triggered activity in patients with paroxysmal AF and to determine whether these cellular events contribute to initiation and recurrence of $\mathrm{AF}$ episodes in these patients.

\section{AF-induced structural remodelling versus primary atrial cardiomyopathy}

Despite years of research and advances in catheter-based therapies for AF, we are still striving to understand the reasons for the development of AF and the mechanisms underlying the structural abnormalities in atrial walls observed in patients with the arrhythmia. The common perception that
$\mathrm{AF}$ is the result of interplay between the structural changes in the atrial myocardium induced by the well-described cardiovascular disease risk factors and structural remodelling induced by the arrhythmia itself has recently been challenged by observations of progressive structural abnormalities in the atrial walls that occur independently from the cardiovascular comorbidities and persistency of AF [23]. However to what extent this fibrotic atrial cardiomyopathy represents a 'common cause' of AF or a mechanism responsible for arrhythmia development in a subgroup of patients with AF phenotype remains uncertain.

One of the first observations that challenged the causative relationship between $\mathrm{AF}$ and development of atrial fibrosis came from an experimental study demonstrating that atrial pacing-induced $\mathrm{AF}$ per se did not result in any detectable fibrosis development, whereas induction of congestive heart failure was associated with AF inducibility and led to significant fibrotic transformation of atrial myocardium [24]. In humans, an indirect indication of the link between cardiovascular comorbidities and AF comes from epidemiological studies, in which potentially fibrosis-causing conditions such as hypertension, ischaemic heart disease and diabetes are highly predictive of incident AF [25]. An agerelated increase in the prevalence of AF has also been well-documented [26] and explained by growing cardiovascular disease burden in the elderly as well as an age-related increase in the extent of atrial fibrosis [27]. However, attempts to provide a quantitative assessment of atrial structural abnormalities associated with AF have demonstrated a more complex picture. Even though catheter-based techniques of endocardial voltage mapping and emerging noninvasive MRI have been valuable for visualization of atrial structural abnormalities, histological evaluation of atrial tissue samples remains the gold standard for tissue characterization. This approach, however, is often limited to a small volume of tissue samples that can be collected in patients undergoing atrial biopsy or confined to right or left atrial appendages in patients undergoing open-chest heart surgery, thus imposing a significant bias on patient selection and leaving large portions of atrial walls, in which AF perpetuates, unattainable.

In a postmortem study that included atrial tissue samples collected from multiple locations in the right and left atria in patients with paroxysmal AF, permanent AF or no history of AF in a $1: 1: 1$ 

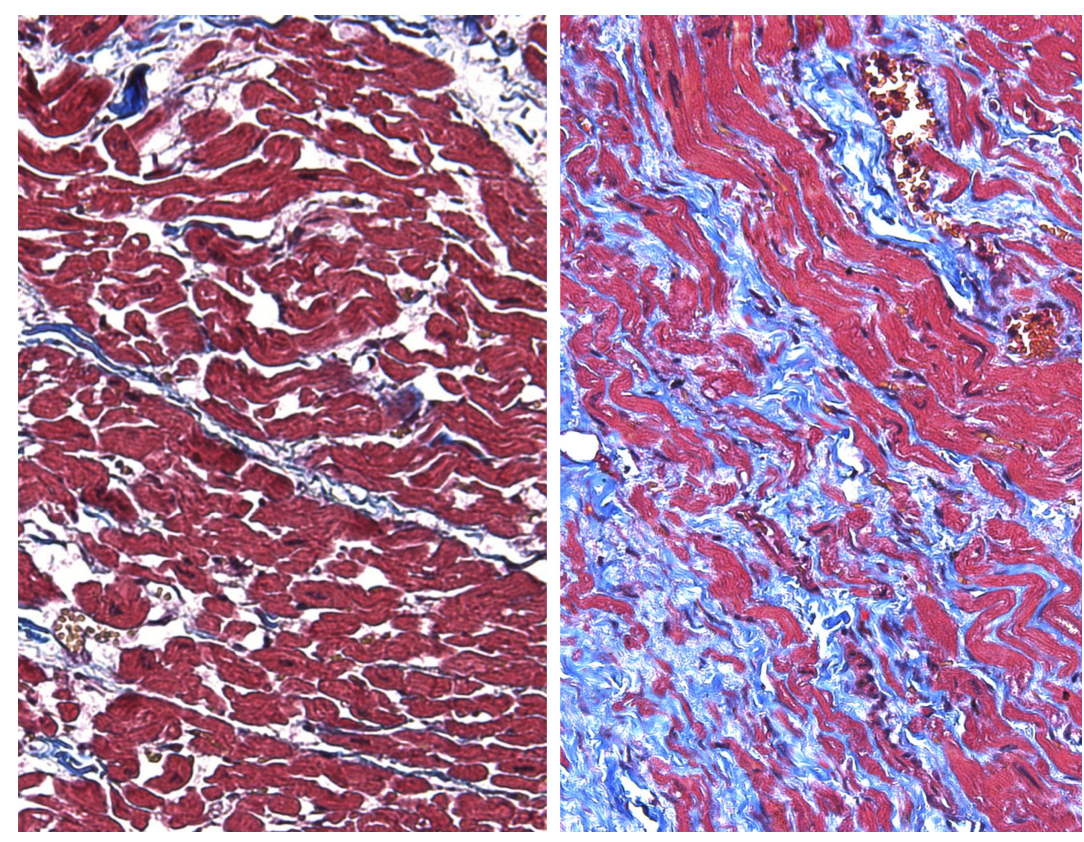

Fig. 2 Light microscopy of crista terminalis specimens from patients without a history of atrial fibrillation (AF) (left) and with permanent $A F$ (right). Note the widespread interstitial fibrosis and distuption of myocardial bundles in the permanent $A F$ specimen. Masson's trichrome stain; original magnification $\times 200$. Courtesy of Dr. Lubov Mitrofanova. fashion according to prespecified inclusion criteria [28], the extent of fibrosis and fatty tissue in the atrial myocardium showed strong and significant correlation with the presence of $\mathrm{AF}$ at all tissue sampling locations in the left and right atria (see examples in Fig. 2). Notably, patients with and without AF did not differ in regard to cardiovascular comorbidities and no age-related increase in the extent of atrial fibrosis was evident. Similar observations were made in patients with persistent or long-standing AF referred for surgical ablation [29], thus suggesting that development of structural abnormalities in the atria is not a result of concomitant diseases but rather a phenomenon associated with AF. Indirect assessment of atrial fibrosis using MRI in a large cohort has further supported this theory as no significant differences in the estimated extent of fibrosis between $\mathrm{AF}$ patients with and without comorbidities were found [30]. To our knowledge, however, no histological studies have been conducted to specifically address the issue of causal relationships between the burden of concomitant cardiovascular diseases and atrial fibrosis in patients with AF.

However, whether or not structural abnormalities observed in the atria are the cause or consequence of AF remains unclear. Indeed, the presence of a relationship between the extent of fibrosis and $\mathrm{AF}$ burden could be explained in one of two ways: extensive fibrosis in the atria may promote persis- tent $\mathrm{AF}$ or may be a consequence of the longstanding fibrillatory process. The lack of this relationship, however, would favour the concept that the primary fibrotic atrial cardiomyopathy underlies AF development. Available data suggest that the extent of fibrosis tends to be higher in patients with permanent AF compared with those with paroxysmal AF [28] but the relationship between the extent of structural abnormalities and duration of AF seems to disappear in patients with persistent AF [29]. In another study in which the expression of extracelluar matrix proteins in atrial tissue samples collected during heart surgery was quantified, no systematic differences between patients with paroxysmal and permanent AF were observed [31]. Even though this does not address the unresolved causality issue, it could be speculated that the extent of fibrosis in the atrial walls may be linked to AF burden and clinical manifestations of the arrhythmia at the early stages of the disease but upon reaching a certain level would no longer affect $\mathrm{AF}$ phenotype in patients who develop persistent AF.

Long-term observational studies would be able to resolve this controversy if they were able to show that successful rhythm-control intervention slows or abolishes progression of the atrial structural changes; however, direct histological evidence of this cause-effect relationship is lacking at present. By contrast, the first proof of progressive atrial 
Table 1 Overview of the most important structural alterations in atrial tissue associated with or predisposing to atrial fibrillation $(A F)$

\begin{tabular}{|c|c|c|c|}
\hline & Structural/biochemical alteration & Functional consequence & $\begin{array}{l}\text { Key } \\
\text { references }\end{array}$ \\
\hline \multirow{8}{*}{$\begin{array}{l}\text { Alterations } \\
\text { promoting } \\
\text { conduction } \\
\text { disturbances } \\
\text { and reentry }\end{array}$} & Interstitial and replacement fibrosis & $\begin{array}{l}\text { Electrical dissociation, conduction } \\
\text { block, macro-reentry }\end{array}$ & {$[27,48,49]$} \\
\hline & Endomysial fibrosis related to AF & $\begin{array}{l}\text { Electrical dissociation, high AF } \\
\text { complexity, micro-reentry, endo- } \\
\text { epicardial dissociation }\end{array}$ & {$[50,51]$} \\
\hline & Inflammatory infiltration & Induction of profibrotic responses & {$[52]$} \\
\hline & Fatty infiltration & $\begin{array}{l}\text { Induction of profibrotic and } \\
\text { pro-inflammatory reactions, } \\
\text { conduction disturbances }\end{array}$ & {$[53,54]$} \\
\hline & Amyloidosis & Conduction disturbances & {$[55,56]$} \\
\hline & Gap junction alterations & Conduction disturbances & [57] \\
\hline & Myocyte hypertrophy & $\begin{array}{l}\text { Aggravation of conduction } \\
\text { disturbances }\end{array}$ & {$[58]$} \\
\hline & Apoptosis/myocyte death & Induction of profibrotic alterations & {$[24]$} \\
\hline $\begin{array}{l}\text { Ion channel } \\
\text { remodelling }\end{array}$ & $\begin{array}{l}\text { AF cycle length shortening (if due to atrial } \\
\text { tachycardia), AF cycle length prolongation } \\
\text { (if due to heart failure), enhanced } \\
\text { heterogeneity of atrial repolarization }\end{array}$ & $\begin{array}{l}\text { Variable changes in wavelength, } \\
\text { enhanced heterogeneity of atrial } \\
\text { refractoriness }\end{array}$ & {$[17,59,60]$} \\
\hline \multirow{2}{*}{$\begin{array}{l}\text { Changes inducing/ } \\
\text { promoting ectopy }\end{array}$} & $\mathrm{Ca}^{2+}$-handling instability & Increased propensity to ectopy & {$[9,12-15]$} \\
\hline & Sympathetic hyperinnervation & $\begin{array}{l}\text { Enhanced release of catecholamines, } \\
\text { enhanced propensity to ectopy }\end{array}$ & {$[61,62]$} \\
\hline \multirow[t]{2}{*}{$\begin{array}{l}\text { Vascular and } \\
\text { prothrombotic } \\
\text { alterations }\end{array}$} & Microvascular rarefaction & $\begin{array}{l}\text { Aggravation of atrial ischaemia, } \\
\text { heterogeneity of electrical function, } \\
\text { structural remodelling }\end{array}$ & {$[63]$} \\
\hline & Endocardial remodelling & Enhanced risk of thrombus formation & [64] \\
\hline
\end{tabular}

remodelling after successful catheter ablation was reported from a small cohort study of patients who demonstrated a further decrease in atrial electrogram voltage and further slowing of atrial conduction velocity 1 year after pulmonary vein isolation [32]. To what extent these findings can be generalized to a larger population of patients with $\mathrm{AF}$ remains to be investigated.

Table 1 provides an overview of the most relevant pathophysiological alterations associated with or predisposing to $\mathrm{AF}$.

\section{Multiple wavelet hypothesis versus rotors}

Another central topic of debate is the analysis and interpretation of electrograms during AF. Defining the sequence of activation during AF is fundamental to the understanding of the pathophysiology of AF. The current diversity in the perception of different mechanisms sustaining AF is partly due to the fact that no consensus has been achieved so far with regards to minimal requirements for electrogram recordings and analysis or the interpretation of electrograms during AF. 
Traditionally, AF was thought to be sustained by multiple wavelets, as proposed by Moe in the late 1950s [33]. According to this hypothesis, continuous wavefront-wavetail interactions lead to wavebreak and generation of new wavefronts while the number of fibrillation waves tends to be reduced by collision and fusion. As long as the number of fibrillation waves stays above a critical number, multiple wavelets are able to sustain AF. The multiple wavelet hypothesis is supported by much experimental evidence ranging from the initial observation of numerous independent wavefronts in canine atria exposed to acetylcholine [34] to the finding of multiple wavelets in patients with $\mathrm{AF}$ based on ECG imaging [35] and epicardial highdensity mapping in patients undergoing open chest surgery [36, 37].

Spiral wave reentry or rotors were identified in the atria more than 90 years ago [38]. In the 1970s Allessie et al. [39] demonstrated in rabbit atria that rotating reentry does not require an anatomical obstacle. More recently, Mandapati et al. [40] identified rotors driving $\mathrm{AF}$ in isolated sheep atria exposed to acethylcholine. A comparison of mechanisms underlying spiral wave reentry and multiple wavelets is shown in Fig. 3.

Recently, several groups have demonstrated rotors driving AF in humans. Using phase analysis of endocardial atrial electrograms recorded with a basket catheter, Narayan et al. [41] demonstrated rotors in both the right and left atria. Many of these rotors are detectable for many seconds up to minutes at the same location [42]. Ablation of the core of these rotors and focal sources [focal impulse and rotor modulation (FIRM)] led to termination of $\mathrm{AF}$ in $86 \%$ of the patients $(72 \%$ with persistent $\mathrm{AF}$ and $28 \%$ with paroxysmal $\mathrm{AF}$ ) [41]. In a more recently published report from a multicentre FIRM registry, single-procedure freedom from AF after a follow-up of 1 year was approximately $80 \%$ and similar in patients with paroxysmal or persistent AF [43].

Using a completely different approach, Haissaguerre et al. [44] have also detected rotors. They used ECG imaging, a technique which allows the reconstruction of conduction patterns in the heart based on an array of body surface electrograms and the individual anatomy of the thorax from thoracic CT or MRI. This technique shows driver regions consisting of rotors (80\%) and focal breakthroughs $(20 \%)$. The driver regions were not spatially stable but occurred at preferential sites visualized by an automatically calculated cumulative source density map. Overall, $70 \%$ of the drivers occurred in the left atrium. Ablation of the drivers resulted in termination of AF in $75 \%$ of patients with persistent AF; $85 \%$ of patients with persistent AF were still in sinus rhythm after 1 year (comparable to the control group undergoing stepwise ablation) but the radiofrequency delivery (a)

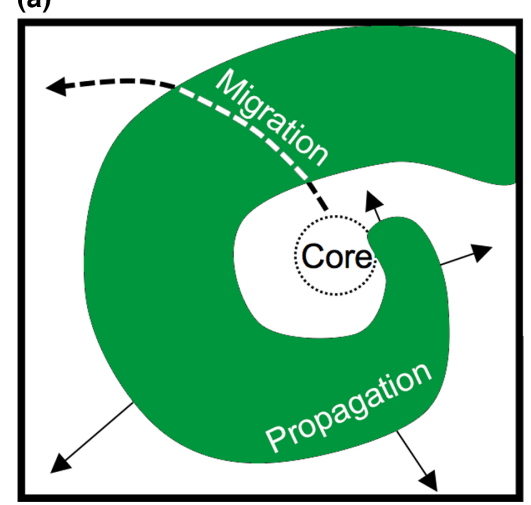

(b)

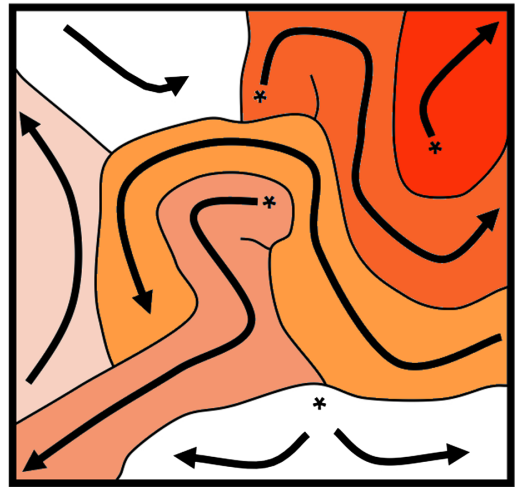

Fig. 3 (a) Spiral wave reentry. The activation wavefronts turn around a core which represents an anatomical obstacle for conduction. Typically, the conduction velocity decreases towards the core of rotation because the source-sink mismatch shifts increasingly towards the sink. The core is unexcited, but excitable, and can migrate through excitable tissue and may anchor at sites with a short refractory period or enhanced sink (branching points of muscle bundles). (b) Multiple wavelet reentry. Waves (different grey scales) are separated by multiple lines of conduction block. Asterisks show 'breakthroughs' which are due to transmural conduction originating from deeper layers of the atrial wall [three-dimensional substrate for atrial fibrillation $(A F)]$. 
time was shortened to less than $50 \%$ as compared to the control group suggesting that targeting rotors identified by ECG imaging is a very effective intervention to destabilize AF.

Despite the very promising results presented from studies targeting rotors for ablation of $\mathrm{AF}$, many questions essential to the understanding of the role of rotors in $\mathrm{AF}$ and of the mechanisms of $\mathrm{AF}$ in general remain unanswered. First, it is clear that detection of rotors using basket mapping data and FIRM provides fundamentally different results regarding the spatial behaviour of rotors as compared to ECG imaging. Whereas FIRM demonstrates spatially stable rotors with hundreds of revolutions taking place at one specific site, ECG imaging as conducted by Haisssaguere et al. shows that the reentrant circuits are not spatially stable but migrate throughout the atrium. Nevertheless, they occur preferentially at specific sites that may provide a target for ablation. The reason for this significant discrepancy between the spatial behaviour of rotors identified by these different techniques is currently unclear.

A very striking distinction between the new mapping techniques and direct contact mapping is the huge difference in complexity. While ECG imaging can detect between two and 10 simultaneous fibrillation waves in patients with persistent $\mathrm{AF}$ [35], the number of simultaneous waves identified by direct contact mapping is 0.5 per $\mathrm{cm}^{2}$ which is equivalent to at least 100 simultaneous waves in total [37]. It is possible that the considerable difference in $\mathrm{AF}$ complexity between FIRM and ECG imaging on the one hand and direct contact mapping on the other is related to preprocessing of the electrograms. Both ECG imaging and basket mapping use phase analysis to determine rotational conduction behaviour during AF. A repetitive phenomenon is described by phase analysis not as its actual state as a function of time but by its phase within a repetitive cycle. A classical example is time, commonly measured as time after midnight. Phase analysis can be performed on signals that show a high degree of periodicity and a monophasic shape. Phase analysis has been used for monophasic or optical action potential data or for ventricular electrograms which show a more regular and monophasic shape. Atrial electrograms show a high degree of fractionation and therefore need to be preprocessed to allow for a meaningful analysis of phase [45]. This preprocessing must contain a strong element of spatial or temporal filtering and smoothing so that fractiona- tion is fully removed from the signals. It is currently unclear how far this massive prefiltering step affects the conduction pattern determined by these techniques but it is reasonable to assume that any smoothing and major filtering will reduce the detected complexity of AF.

Finally, the relation between the identified conduction patterns and the anatomy of the atrium has not been addressed in detail in studies using FIRM. The use of high-density direct contact mapping has provided evidence that the anatomy of endocardial atrial trabeculae and muscle bundles as well as the fibre orientation in the epicardial layer constitute important determinants of direction and preferentiality of fibrillation waves [46], however, no such data have been provided using FIRM. The spatial distribution of the identified sources of AF has been described but the location of important anatomical structures such as the pulmonary veins is often not included in the graphical depictions or movies showing stable rotors identified by basket mapping. Thus, relevant issues remain to be addressed, such as whether the stability of some of the reported rotors is related to reentry around the pulmonary veins.

Unfortunately, many details of the algorithms used for the analysis of ECG imaging and for FIRM have not been disclosed. Investigators studying AF conduction patterns by direct contact mapping have provided detailed information on assumptions, definitions and algorithms of the quantitative parameters used [36, 37, 45, 47], but such description is largely lacking in the case of ECG imaging and FIRM. It is clear that in these cases the economic interests of the intellectual property holders of these techniques compete with the principle of transparency of scientific research and the culture of sharing methods and results within the scientific community.

\section{A plea for transparency in translational electrophysiology}

The translation of data from basic science and animal studies into clinical practice is one of the most important goals of medical research and the foundation of intense research interest. The considerable expense associated with basic and experimental research and the required extensive funding may at last receive social justification if this research finally leads to a transfer of knowledge to clinical medicine and, thereby, to a recognizable improvement of patient care. Extensive exchange and cooperation between basic research 
scientists and clinicians is essential for the promotion of this translational process. Subsequently, rapid translation is crucial to achieve wider application and thus easier confirmation and reproduction of results derived from implementation of novel methods and technologies. An open approach with extensive disclosure of research data and of technical details is not only undoubtedly an ethically superior approach, but is also beneficial for clinical scientists as this is the fastest way for wide acceptance of novel ideas and ultimately for scientific recognition of research work. Financial considerations of possible benefits deriving for example from patented algorithms or techniques may impose barriers to such an open approach. However, the current practice of very successful large corporations exhibiting astonishing openness in this context may serve as an example that this openness is not necessarily disadvantageous. We believe that it is essential that all stakeholders in the field, including scientists and business developers as well the editors of major scientific journals, recognize their particular responsibility to promote open and reliable access to scientific data for the successful future of basic and clinical science.

\section{Conflict of interest statement}

None of the authors have any conflicts of interest to declare.

\section{Funding}

This work was supported by a grant from the European Network for Translational Research in Atrial Fibrillation (EUTRAF; grant number 261057) to DD and US and a grant from the German Federal Ministry of Education and Research through the German Center for Cardiovascular Research (DZHK) to DD. This work was also supported by a grant from the Netherlands Heart Foundation (CVON; grant number 2014-09) and from the European Union (CATCH ME, No. 633196, AFib TrainNet, No. 675351) to US. PP is supported by The Swedish Heart-Lung Foundation (grant numbers 20140734 and 20110875).

\section{References}

1 Kirchhof $\mathrm{P}$, Breithardt G, Aliot $\mathrm{E}$ et al. Personalized management of atrial fibrillation: proceedings from the fourth Atrial Fibrillation competence NETwork/European Heart Rhythm
Association consensus conference. Europace. 2013;15:154056.

2 Lau DH, Volders PG, Kohl P et al. Opportunities and challenges of current electrophysiology research: a plea to establish 'translational electrophysiology' curricula. Europace 2015; 17: 825-33.

3 Heijman J, Voigt N, Nattel S, Dobrev D. Cellular and molecular electrophysiology of atrial fibrillation initiation, maintenance, and progression. Circ Res 2014; 114: 1483-99.

4 Sood S, Chelu MG, vanOort RJ et al. Intracellular calcium leak due to FKBP12.6 deficiency in mice facilitates the inducibility of atrial fibrillation. Heart Rhythm. 2008;5:1047-54.

5 Beavers DL, Wang W, Ather S et al. Mutation E169K in junctophilin-2 causes atrial fibrillation due to impaired RyR2 stabilization. J Am Coll Cardiol 2013; 62: 2010-9.

6 Shan J, Xie W, Betzenhauser M et al. Calcium leak through ryanodine receptors leads to atrial fibrillation in 3 mouse models of catecholaminergic polymorphic ventricular tachycardia. Circ Res 2012; 111: 708-17.

7 Chelu MG, Sarma S, Sood S et al. Calmodulin kinase IImediated sarcoplasmic reticulum $\mathrm{Ca}^{2+}$ leak promotes atrial fibrillation in mice. J Clin Investig 2009; 119: 1940-51.

8 Li N, Wang T, Wang W et al. Inhibition of CaMKII phosphorylation of RyR2 prevents induction of atrial fibrillation in FKBP12.6 knockout mice. Circ Res 2012; 110: 465-70.

9 Vest JA, Wehrens XH, Reiken SR et al. Defective cardiac ryanodine receptor regulation during atrial fibrillation. Circulation 2005; 111: 2025-32.

10 Yeh YH, Wakili R, Qi XY et al. Calcium-handling abnormalities underlying atrial arrhythmogenesis and contractile dysfunction in dogs with congestive heart failure. Circ Arrhythm Electrophysiol 2008; 1: 93-102.

11 Greiser M, Neuberger HR, Harks E et al. Distinct contractile and molecular differences between two goat models of atrial dysfunction: AV block-induced atrial dilatation and atrial fibrillation. J Mol Cell Cardiol 2009; 46: 385-94.

12 Hove-Madsen L, Llach A, Bayes-Genis A et al. Atrial fibrillation is associated with increased spontaneous calcium release from the sarcoplasmic reticulum in human atrial myocytes. Circulation 2004; 110: 1358-63.

13 Neef S, Dybkova N, Sossalla S et al. CaMKII-dependent diastolic SR Ca2 + leak and elevated diastolic Ca2 + levels in right atrial myocardium of patients with atrial fibrillation. Circ Res 2010; 106: 1134-44.

14 Voigt N, Li N, Wang Q et al. Enhanced sarcoplasmic reticulum $\mathrm{Ca}^{2+}$ leak and increased $\mathrm{Na}^{+}-\mathrm{Ca}^{2+}$ exchanger function underlie delayed afterdepolarizations in patients with chronic atrial fibrillation. Circulation 2012; 125: 2059-70.

15 Greiser M, Kerfant BG, Williams GS et al. Tachycardiainduced silencing of subcellular $\mathrm{Ca}^{2+}$ signaling in atrial myocytes. J Clin Investig 2014; 124: 4759-72.

16 Wakili R, Yeh YH, Yan QX et al. Multiple potential molecular contributors to atrial hypocontractility caused by atrial tachycardia remodeling in dogs. Circ Arrhythm Electrophysiol. 2010;3:530-41.

17 Grandi E, Pandit SV, Voigt $\mathrm{N}$ et al. Human atrial action potential and $\mathrm{Ca} 2+$ model: sinus rhythm and chronic atrial fibrillation. Circ Res 2011; 109: 1055-66.

18 Voigt N, Heijman J, Wang Q et al. Cellular and molecular mechanisms of atrial arrhythmogenesis in patients with paroxysmal atrial fibrillation. Circulation 2014; 129: 145-56. 
19 Christ T, Rozmaritsa N, Engel A et al. Arrhythmias, elicited by catecholamines and serotonin, vanish in human chronic atrial fibrillation. Proc Natl Acad Sci USA 2014; 111: 111938.

20 Li N, Chiang DY, Wang S et al. Ryanodine receptor-mediated calcium leak drives progressive development of an atrial fibrillation substrate in a transgenic mouse model. Circulation 2014; 129: 1276-85.

21 King JH, Zhang Y, Lei M, Grace AA, Huang CL, Fraser JA. Atrial arrhythmia, triggering events and conduction abnormalities in isolated murine RyR2-P2328S hearts. Acta Physiol 2013; 207: 308-23.

22 King JH, Wickramarachchi C, Kua K et al. Loss of Nav1.5 expression and function in murine atria containing the RyR2P2328S gain-of-function mutation. Cardiovasc Res. 2013;99:751-9.

23 Kottkamp H. Fibrotic atrial cardiomyopathy: a specific disease/syndrome supplying substrates for atrial fibrillation, atrial tachycardia, sinus node disease, AV node disease, and thromboembolic complications. $J$ Cardiovasc Electrophysiol 2012; 23: 797-9.

24 Aime-Sempe C, Folliguet T, Rucker-Martin C et al. Myocardial cell death in fibrillating and dilated human right atria. J Am Coll Cardiol 1999; 34: 1577-86.

25 Smith JG, Newton-Cheh C, Almgren P et al. Assessment of conventional cardiovascular risk factors and multiple biomarkers for the prediction of incident heart failure and atrial fibrillation. J Am Coll Cardiol 2010; 56: 1712-9.

26 Smith JG, Platonov PG, Hedblad B, Engstrom G, Melander O. Atrial fibrillation in the Malmo Diet and Cancer study: a study of occurrence, risk factors and diagnostic validity. Eur $J$ Epidemiol 2010; 25: 95-102.

27 Gramley F, Lorenzen J, Knackstedt C et al. Age-related atrial fibrosis. Age 2009; 31: 27-38.

28 Platonov PG, Mitrofanova LB, Orshanskaya V, Ho SY. Structural abnormalities in atrial walls are associated with presence and persistency of atrial fibrillation but not with age. $J$ Am Coll Cardiol 2011; 58: 2225-32.

29 Corradi D, Callegari S, Manotti L et al. Persistent lone atrial fibrillation: clinicopathologic study of 19 cases. Heart Rhythm 2014; 11: 1250-8.

30 Mahnkopf C, Badger TJ, Burgon NS et al. Evaluation of the left atrial substrate in patients with lone atrial fibrillation using delayed-enhanced MRI: implications for disease progression and response to catheter ablation. Heart Rhythm 2010; 7: 1475-81.

31 Boldt A, Wetzel U, Lauschke $\mathrm{J}$ et al. Fibrosis in left atrial tissue of patients with atrial fibrillation with and without underlying mitral valve disease. Heart 2004; 90: 400-5.

32 Teh AW, Kistler PM, Lee G et al. Long-term effects of catheter ablation for lone atrial fibrillation: progressive atrial electroanatomic substrate remodeling despite successful ablation. Heart Rhythm 2012; 9: 473-80.

33 Moe GK, Abildskov JA. Atrial fibrillation as a self-sustaining arrhythmia independent of focal discharge. Am Heart J 1959; 58: 59-70.

34 Allessie MA, Lammers W.J.E.P. et al. Experimental evaluation of Moe's multiple wavelet hypothesis of atrial fibrillation. In: Zipes DP, Jalife J, eds. Cardiac Arrhythmias. New York: Grune \& Stratton, 1985; 265-76.

35 Cuculich PS, Wang Y, Lindsay BD et al. Noninvasive characterization of epicardial activation in humans with diverse atrial fibrillation patterns. Circulation 2010; 122: 1364-72.

36 Lee G, Kumar S, Teh A et al. Epicardial wave mapping in human long-lasting persistent atrial fibrillation: transient rotational circuits, complex wavefronts, and disorganized activity. Eur Heart J 2014; 35: 86-97.

37 Allessie MA, de Groot NM, Houben RP et al. Electropathological substrate of long-standing persistent atrial fibrillation in patients with structural heart disease: longitudinal dissociation. Circ Arrhythm Electrophysiol 2010; 3: 606-15.

38 Garrey W. Auricular fibrillation. Physiol Rev 1924; 4: 215250.

39 Allessie MA, Bonke FI, Schopman FJ. Circus movement in rabbit atrial muscle as a mechanism of trachycardia. Circ Res 1973; 33: 54-62.

40 Mandapati R, Skanes A, Chen J, Berenfeld O, Jalife J. Stable microreentrant sources as a mechanism of atrial fibrillation in the isolated sheep heart. Circulation 2000; 101: 194-9.

41 Narayan SM, Krummen DE, Shivkumar K, Clopton P, Rappel WJ, Miller JM. Treatment of atrial fibrillation by the ablation of localized sources: CONFIRM (Conventional Ablation for Atrial Fibrillation With or Without Focal Impulse and Rotor Modulation) trial. $J$ Am Coll Cardiol 2012; 60: 628-36.

42 Swarup V, Baykaner T, Rostamian A et al. Stability of rotors and focal sources for human atrial fibrillation: focal impulse and rotor mapping (FIRM) of AF sources and fibrillatory conduction. J Cardiovasc Electrophysiol 2014; 25: 1284-92.

43 Miller JM, Kowal RC, Swarup V et al. Initial independent outcomes from focal impulse and rotor modulation ablation for atrial fibrillation: multicenter FIRM registry. $J$ Cardiovasc Electrophysiol 2014; 25: 921-9.

44 Haissaguerre M, Hocini M, Denis A et al. Driver domains in persistent atrial fibrillation. Circulation 2014; 130: 530-8.

45 Kuklik P, Zeemering S, Maesen B et al. Reconstruction of instantaneous phase of unipolar atrial contact electrogram using a concept of sinusoidal recomposition and Hilbert transform. IEEE Transact Biomed Eng 2015; 62: 296-302.

46 Maesen B, Zeemering S, Afonso C et al. Rearrangement of atrial bundle architecture and consequent changes in anisotropy of conduction constitute the 3-dimensional substrate for atrial fibrillation. Circ Arrhythm Electrophysiol 2013; 6: 967-75.

47 Zeemering S, Maesen B, Nijs J et al. Automated quantification of atrial fibrillation complexity by probabilistic electrogram analysis and fibrillation wave reconstruction. Conf Proc IEEE Eng Med Biol Soc 2012; 2012: 6357-60.

48 Anne W, Willems R, Roskams $\mathrm{T}$ et al. Matrix metalloproteinases and atrial remodeling in patients with mitral valve disease and atrial fibrillation. Cardiovasc Res 2005; 67: 65566.

49 Chimenti C, Russo MA, Carpi A, Frustaci A. Histological substrate of human atrial fibrillation. Biomed Pharmacother. 2010;64:177-83.

50 Eckstein J, Zeemering S, Linz D et al. Transmural conduction is the predominant mechanism of breakthrough during atrial fibrillation: evidence from simultaneous endo-epicardial high-density activation mapping. Circ Arrhythm Electrophysiol 2013; 6: 334-41. 
51 Verheule S, Tuyls E, Gharaviri A et al. Loss of continuity in the thin epicardial layer because of endomysial fibrosis increases the complexity of atrial fibrillatory conduction. Circ Arrhythm Electrophysiol 2013; 6: 202-11.

52 Frustaci A, Chimenti C, Bellocci F, Morgante E, Russo MA, Maseri A. Histological substrate of atrial biopsies in patients with lone atrial fibrillation. Circulation 1997; 96: $1180-4$.

53 Venteclef N, Guglielmi V, Balse E et al. Human epicardial adipose tissue induces fibrosis of the atrial myocardium through the secretion of adipo-fibrokines. Eur Heart $J$ 2015; 36: 795-805a.

54 Hatem SN, Sanders P. Epicardial adipose tissue and atrial fibrillation. Cardiovasc Res 2014; 102: 205-13.

55 Leone O, Boriani G, Chiappini B et al. Amyloid deposition as a cause of atrial remodelling in persistent valvular atrial fibrillation. Eur Heart J 2004; 25: 1237-41.

56 Rocken C, Peters B, Juenemann G et al. Atrial amyloidosis: an arrhythmogenic substrate for persistent atrial fibrillation. Circulation 2002; 106: 2091-7.

57 Polontchouk L, Haefliger JA, Ebelt B et al. Effects of chronic atrial fibrillation on gap junction distribution in human and rat atria. J Am Coll Cardiol 2001; 38: 883-91.

58 Spach MS, Heidlage JF, Barr RC, Dolber PC. Cell size and communication: role in structural and electrical development and remodeling of the heart. Heart Rhythm 2004; 1: $500-15$.
59 Van Wagoner DR, Pond AL, Lamorgese M, Rossie SS, McCarthy PM, Nerbonne JM. Atrial L-type $\mathrm{Ca}^{2+}$ currents and human atrial fibrillation. Circ Res 1999; 85: 428-36.

60 Dobrev D, Friedrich A, Voigt $\mathrm{N}$ et al. The G protein-gated potassium current $\mathrm{I}(\mathrm{K}, \mathrm{ACh})$ is constitutively active in patients with chronic atrial fibrillation. Circulation 2005; 112: 3697-706.

61 Chen PS, Chen LS, Fishbein MC, Lin SF, Nattel S. Role of the autonomic nervous system in atrial fibrillation: pathophysiology and therapy. Circ Res 2014; 114: 1500-15.

62 Nguyen BL, Fishbein MC, Chen LS, Chen PS, Masroor S, Histopathological substrate for chronic atrial fibrillation in humans. Heart Rhythm 2009; 6: 454-60.

63 Skalidis EI, Hamilos MI, Karalis IK, Chlouverakis G, Kochiadakis GE, Vardas PE. Isolated atrial microvascular dysfunction in patients with lone recurrent atrial fibrillation. $J \mathrm{Am}$ Coll Cardiol 2008; 51: 2053-7.

64 Cai H, Li Z, Goette A et al. Downregulation of endocardial nitric oxide synthase expression and nitric oxide production in atrial fibrillation: potential mechanisms for atrial thrombosis and stroke. Circulation 2002; 106: 2854-8.

Correspondence: Ulrich Schotten, Department of Physiology, Cardiovascular Research Institute Maastricht (CARIM), Maastricht Centre of Systems Biology (MaCSBio), Maastricht University, PO Box 616, 6200 MD Maastricht, The Netherlands. (fax: +31 43388 1077; e-mail: Schotten@maastrichtuniversity. $\mathrm{nl})$. 